\title{
APPLICATION OF AN AUTONOMOUS/UNMANNED SURVEY VESSEL (ASV/USV) IN BATHYMETRIC MEASUREMENTS
}

\author{
Cezary Specht \\ Emilian Świtalski \\ Mariusz Specht \\ Gdynia Maritime University, Poland
}

\begin{abstract}
The accuracy of bathymetric maps, especially in the coastal zone, is very important from the point of view of safety of navigation and transport. Due to the continuous change in shape of the seabed, these maps are fast becoming outdated for precise navigation. Therefore, it is necessary to perform periodical bathymetric measurements to keep them updated on a current basis. At present, none of the institutions in Poland (maritime offices, Hydrographic Office of the Polish Navy) which are responsible for implementation of this type of measurements has at their disposal a hydrographic vessel capable of carrying out measurements for shallow waters (at depths below $1 \mathrm{~m}$ ). This results in emergence of large areas for which no measurement data have been obtained and, consequently, the maps in the coastal zones are rather unreliable.

The article presents the concept of bathymetric measurements for shallow waters with the use of an autonomous, unmanned survey vessel (ASV/USV). For this purpose, the authors modernized a typical ASV/USV unit with standard radio remote control system to the fully autonomous mode. As part of the modernization, the route planning software was created. The developed software works based on, alternatively, GNSS measurements of the coastline, or satellite images. The system was supplemented by an own autopilot (adapted for flying drones). Moreover, the method of controlling electric motors was changed thanks to the use of own electronic circuit.

The modernized ASV/USV measuring system was verified by performing bathymetric measurements of the retention reservoir in Gdansk, Poland. Then, the obtained measurement data were used to create a digital bottom model and a bathymetric map of the reservoir.
\end{abstract}

Keywords: autonomous, unmanned survey vessel (ASV/USV), bathymetric measurements, digital sea bottom model, bathymetric map

\section{INTRODUCTION}

The beginning of the $21^{\text {st }}$ century is the era of using unmanned boats in various measurement applications $[22,27$, 29]. Modern autonomous and unmanned vessels (Autonomous Surface Vehicle - ASV, Unmanned Surface Vehicle - USV) offer a variety of design solutions in the construction of the hull and the boat propulsion: single hull, double hull with a screw or screwless propulsion with a small draft. They allow the entry into the reservoir with difficult access caused by the presence of shallow waters [22]. Bathymetric surveys being part of hydrographic measurements which aim at measuring the seabed topography require adequate positioning accuracy $[7,9]$, hence the use of unmanned boats in hydrography can now be regarded as the beginning of a new era in this field.
Depending on the size and displacement of the unmanned vessel, its equipment is of vital importance (in particular echo sounder transducers of single and multibeam type). Single beam echo sounders, which can be used here, are small devices that usually do not require Motion Reference Units (MRU) to determine the spatial orientation. Hence, they can be mounted on smaller vessels [12]. Whereas multibeam echo sounders are placed on larger survey vessels [14].

An example of an unmanned hydrographic vessel may be a hydrographic survey drone. Its main advantage is small draft, even when loaded with the echo sounder transducer $(20-30 \mathrm{~cm})$. This allows to perform not only accurate maps of inland waters (including depths below $1 \mathrm{~m}$ ), but also to determine the course of the territorial sea baseline, which in the case of e.g. Poland is usually located at a depth of tens 
of centimetres below the temporary sea level. Previously, the use of manned hydrographic vessels rendered it impossible to perform that type of measurements due to large draft of boats $(0.6-3.3 \mathrm{~m})$ and placing echo sounder transducers on their bows $[25,26]$. It resulted in damage to the measuring equipment and the emergence of large areas for which no measurement data were obtained (bathymetric maps in the coastal zone were unreliable due to the effect of linear interpolation between the coastline and the measurements carried out to the $1 \mathrm{~m}$ contour line) [12]. Therefore, it seems reasonable to make detailed bathymetric measurements for shallow waters to ensure the safety of navigation and transport on these waters $[6,30]$.

\section{AUTONOMOUS CONTROL OF THE UNMANNED SURVEY VESSEL}

The hydrographic survey drone of the Seafloor company required some significant changes to allow for installation of a system ensuring its autonomy. Initially, each of the floats had its own gel battery, along with an $\mathrm{RC}$ receiver, a brushless motor propelling the screw, and the Electronic Speed Control (ESC). The output signals from the receiver were inputs for the ESC. Consequently, each of the floats was an independent system, which prevented the introduction of autonomous control. It was therefore decided to change the structure of the electrical connections in the drone (Fig. 1).
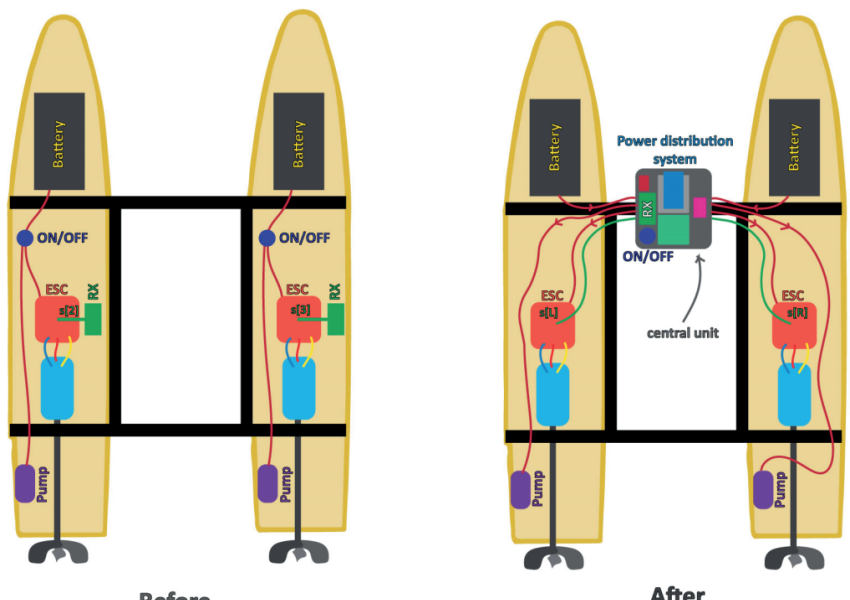

Fig. 1. Differences in electrical connection systems inside the drone (own study)

The designed power distribution system (Figs. 2 and 3) makes it possible to connect 2 gel batteries (terminals $+12 \mathrm{~V} \mathrm{IN}$ ), the main power switch (terminals Switch), the power output, as well as peripherals and outputs, enabling it to apply smooth power control or completely shut off the pumps (terminals Channel 1 OUT and Channel 2 OUT). The implemented power distribution system far exceeds the functionality of the original solution by introducing the main power switch for the entire system, which increases power control capabilities and, above all, the possibilities of control implementation where the work of motors is correlated. The peripherals are powered from a single point, which is beneficial to the distribution of power of the batteries and to the stability of the entire power system.

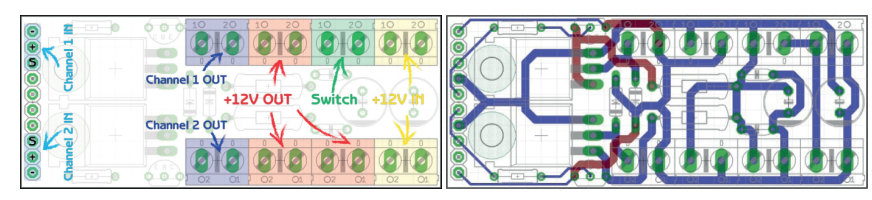

Fig. 2. Connections (left) and paths (right) in the power distribution system (own study)

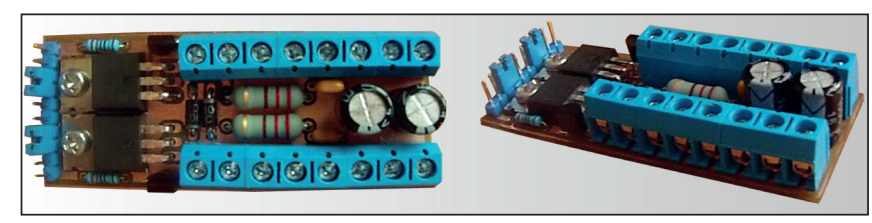

Fig. 3. Power distribution system (own study)

In order to ensure the autonomy of the vessel it was decided to use the Pixhawk autopilot of the 3DR company. For the autopilot to begin sending any signals at the control outputs, all of its components (accelerometer, compass) had to be configured, all peripherals (radio module, GPS receiver) had to be connected, and all security functions related to arming the motors had to be disabled. The mode which seems to be the most optimal for the drone is a "rover" - that is like a car with one engine and a steering axle. However, with 2 engines that proved impossible (due to the lack of a rudder blade). Thus, the authors were forced to build a mixer of control signals which collects power and twist signals, and then, based on these signals, prepares signals for both engines to obtain the desired effect.

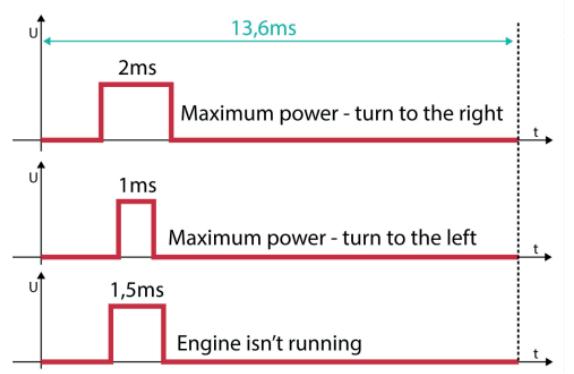

Fig. 4. Interpretation of PPM signals used by ESC (own study)

Most autopilots operate with Pulse Position Modulation (PPM) signals. In the case of service by one channel we are only interested in their width. The pulses may have a width of 1 to $2 \mathrm{~ms} .1 .5 \mathrm{~ms}$ is an average value that in the applied system corresponds with idle (unmoving) screws. At 1 and $2 \mathrm{~ms}$ the engines operate at maximum power, but in the opposite direction. The selected autopilot generates signals with a period of $20 \mathrm{~ms}$, while the ESC units work properly for signals with a period of $13.6 \mathrm{~ms}$. Thus, the mixer of control signals must also change their frequency. 
The ATmega8 microcontroller was used in the construction of the device, as it is cheap and fully sufficient for the realization of the planned task. A quartz crystal resonator $20 \mathrm{Mhz}$ was used as the clock signal source, while the TIMER2 counter and two external interrupts INT0 and INT1 were used to detect the incoming signals. The following code shows the activation of selected peripheries.

int main(void) $\{\ldots$

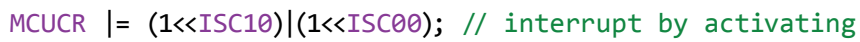

logic state change

GICR $\mid=(1<<$ INT1 $) \mid(1<<$ INT0); // activation INT0 and INT1 interrupts

TCCR2 |= $(1<<C S 22) \mid(1<<C S 2 \theta) ; / /$ activation TIMER2 counter and setting prescaler at 128

... $\}$

Setting the prescaler at 128 causes that a change by 1 in the TCNT2 register occurs at $t_{d}=6.4 \mu \mathrm{s}$. This makes it possible to measure the time at the $t_{d}$ accuracy. TIMER2 is an 8 -bit register. Therefore, one can measure the time with the difference $t_{r}=1.64 \mathrm{~ms}$. This allows measuring the times of 1 to $2 \mathrm{~ms}$. Below the authors present the support for external interrupts.

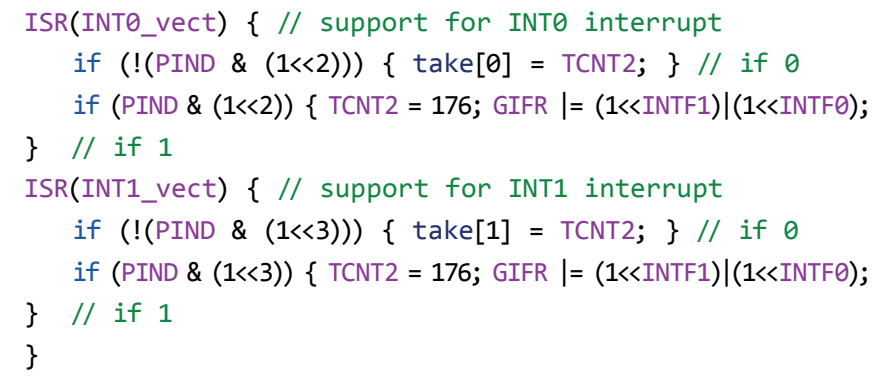

Here, use is made of the fact that signals start at the same time. The occurrence of the signals is indicated by the appearance of 1 at the inputs. This results in setting the TCNT2 register to 176 and zeroing the interrupt flags so that the second interrupt is not implemented before the TIMER1 adds up to 256 - when it passes the value of $\mathrm{t}_{0}=0.512 \mathrm{~ms}$. When zero occurs at one of the channels, then the current value of the TCNT2 register, which contains full information on the pulse duration, is stored.

Output signals were generated using the TIMER1 counter in PWM operational mode, as its use allows to generate a PPM signal. To activate the PWM the previously written library was used:

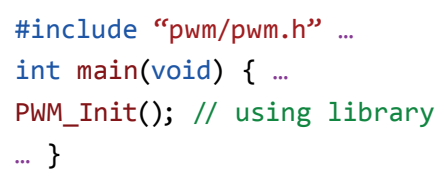

with parameters loaded at the pwm.h header file: \#define PS_PWM 8 // PWM prescaler counter $=8$

\#define ROZ_PWM 17000 // PWM resolution counter = 17000

\#define COM_PWM 1 // filling, ,ones”

\#define ON_PWM outAB // activation OC1A and OC1B

The period of the output pulse amounts to $\mathrm{T}=13.6 \mathrm{~ms}$, which it is exactly what the ESC unit expects. Along with the change of the values of OCR1A and OCR1B registers from 1250 to 2500 , the pulse width can vary from 1 to $2 \mathrm{~ms}$.

Before they get to the output, the measured values have to be subjected to appropriate correction, needed when changing an autopilot/telemanipulator. The microcontroller should keep these corrections in the EEPROM memory, and the signals need to be properly mixed and optionally filtered.

ESC units cannot receive signals immediately after the supply of power, so the mixer of control signals waits a few seconds before it starts sending pulses. This device was designed in the Eagle software (Fig. 5a) and physically built (Fig. 5b).

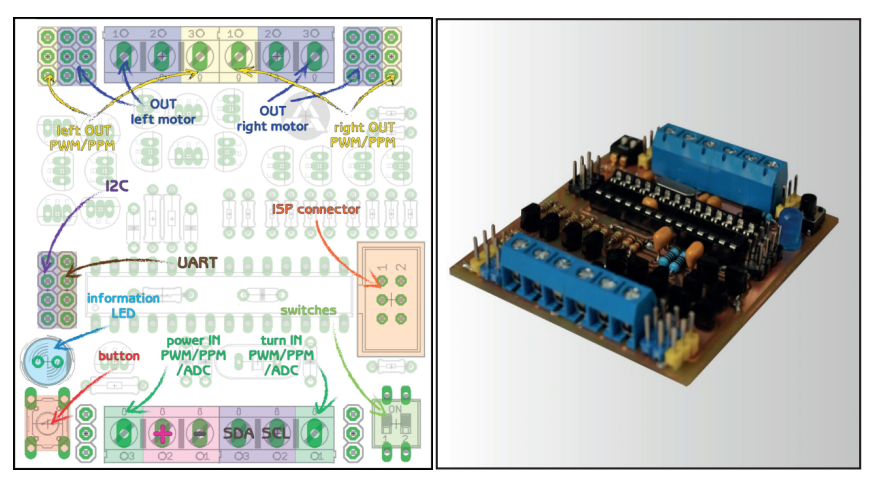

Fig. 5. Outputs (left) and view (right) of the mixer of control signals. (own study)

Both the input and output signals can be different. This fact was taken into account during the design process and the plate is equipped with appropriate infrastructure.

The last built device was a remote switch. Along with the transistorized channels, the switch is used to remotely control the operation of the cooling pumps. It operates as a mixer of control signals, but differs from the mixer in that it uses an ATtiny13A microcontroller and an internal $\mathrm{RC}$ resonator 9.6 $\mathrm{MHz}$, and is much simpler. It receives the signal using the INT0 interrupt, but the output signal is an ordinary PWM with a width from 0 to 255 . In the programme, the input value (take) is appropriately scaled, limited, and entered in the OCR0A register.

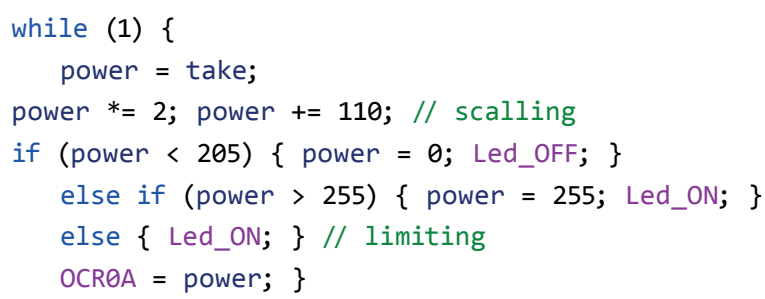


All devices have been properly interconnected and closed in a casing with glands. The $\mathrm{RC}$ receiver passed channels 1 to 5 to the PPM encoder, which then prepared the resulting signal and passed it to the autopilot. Channel 5 was used to switching from manual to automatic mode. Depending on the mode, the autopilot passed signals 1, 3 based on the position of analogue sticks in the telemanipulator, or on the GPS signal. These signals were taken by the mixer of control signals, which generated pulses for the ESC. At the same time Channel 6 of the RC receiver wandered to the remote switch, the output of which was connected to the transistorized channels switching on and off the cooling pumps (Fig. 6).

\section{ROUTE PLANNING SOFTWARE}

In order to determine the drone route, the software for planning the measurement campaign was created in PHP language. The application requires entering: the coordinates of the selection area, the drone position, the coordinates of the directional point, and the distance between the measurement profiles. Based on the drone position and the coordinates of the directional point the direction vector is calculated. Then the entered coordinates are transformed from the geographic coordinate system to the local cartesian coordinate system (with drone position as the origin), which are in turn converted to the polar coordinate system.

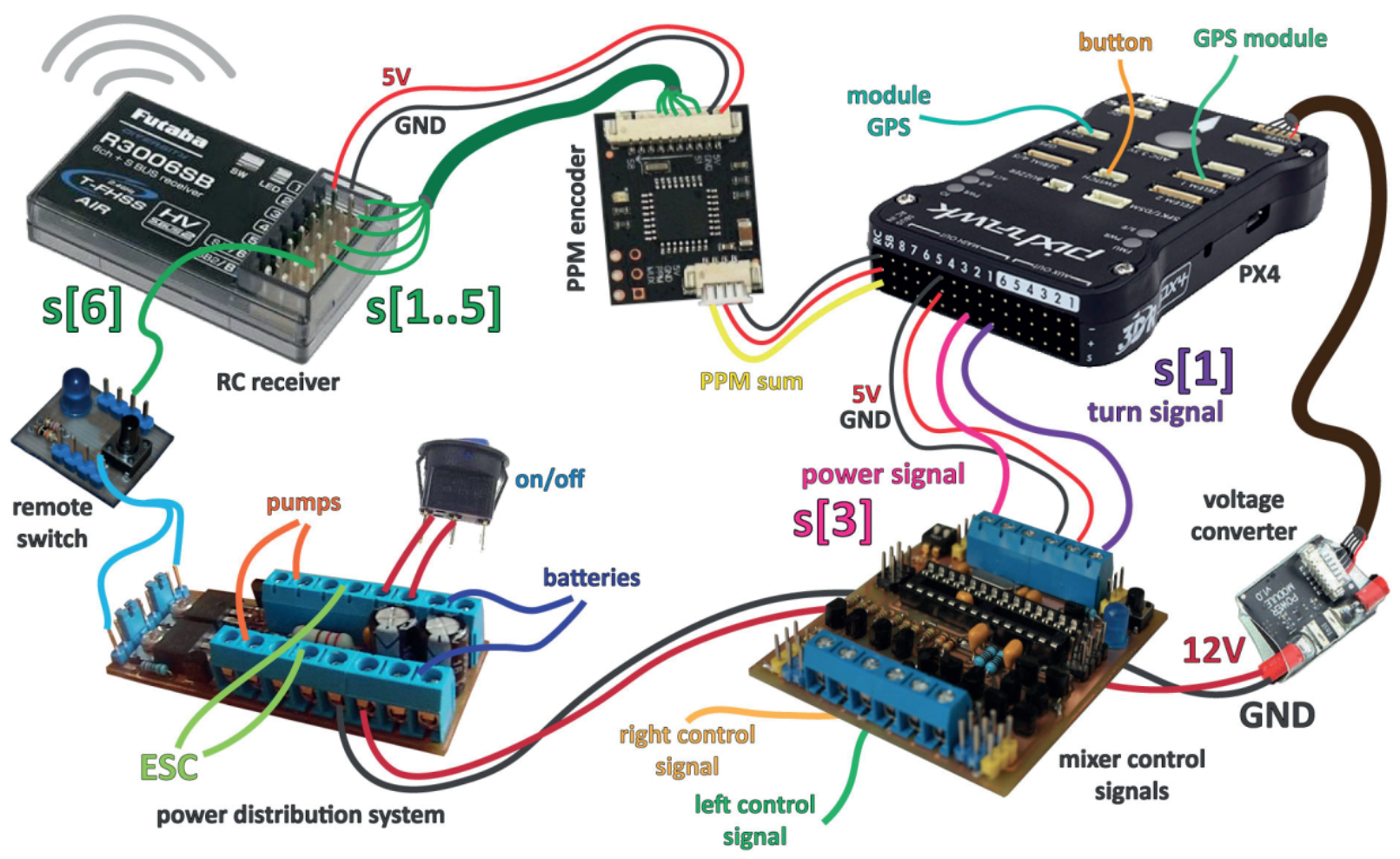

Fig. 6. Schematic diagram of connections in the central unit (own study)
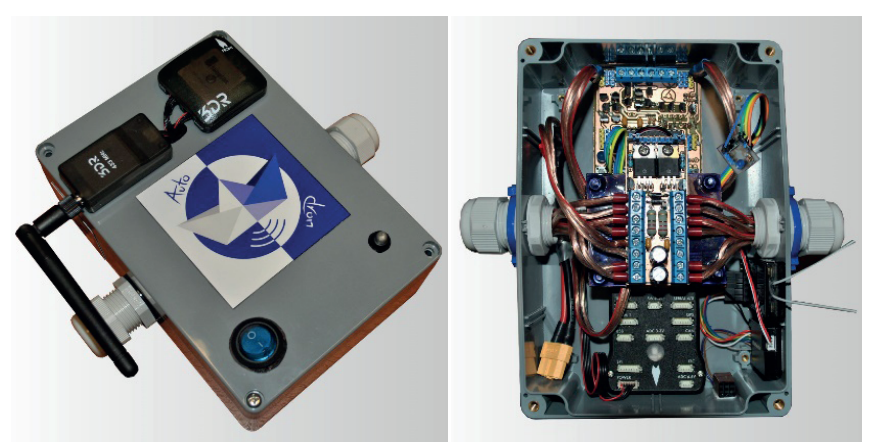

Fig. 7. Central unit (own study)
All points are rotated with respect to the direction vector, that is, the angle formed by that vector with the OX axis is subtracted from each point in the polar system. Then the coordinates are transformed back to the cartesian system. In the system prepared in that way, the coordinates of profile points composing the drone route that are perpendicular to the direction vector are calculated. When this is completed, all operations are carried out in the reverse order until the route in the geographical system is obtained (Fig. 8). The resulting data are prepared in the format suitable for the Mission Planner software of the 3DR company (used to upload the drone route in the autopilot) [25]. 


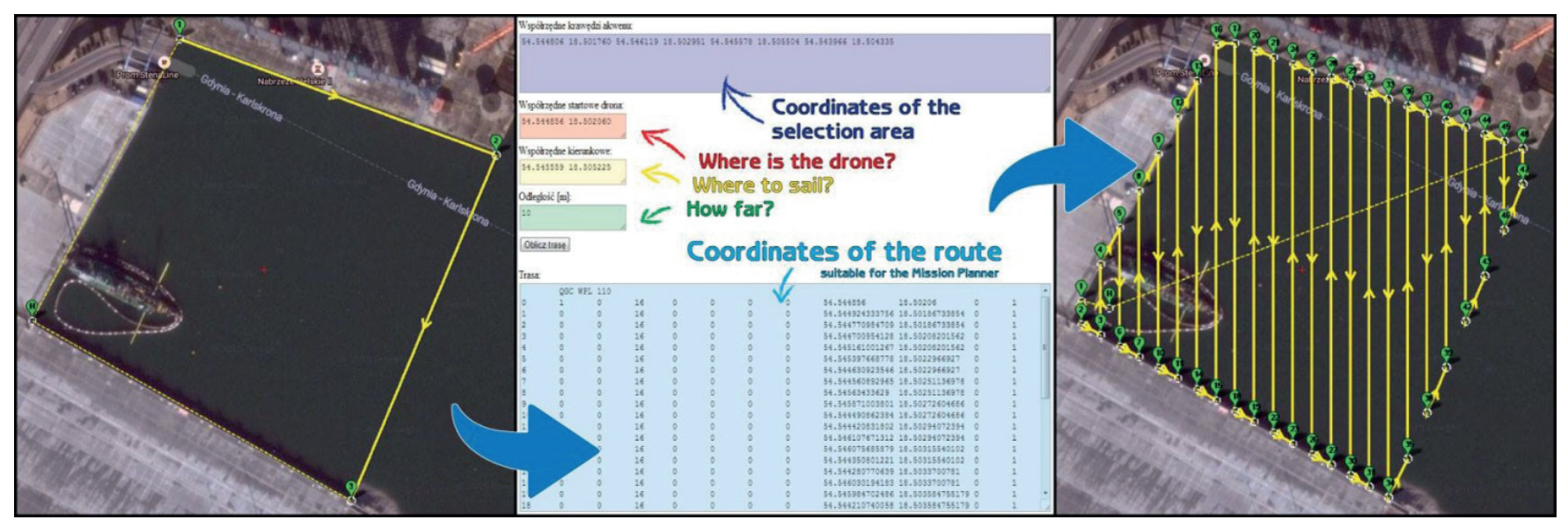

Fig. 8. Application window for planning the measurement campaign (own study)

To make the program more accessible, a simple and intuitive user interface was created (Fig. 9).

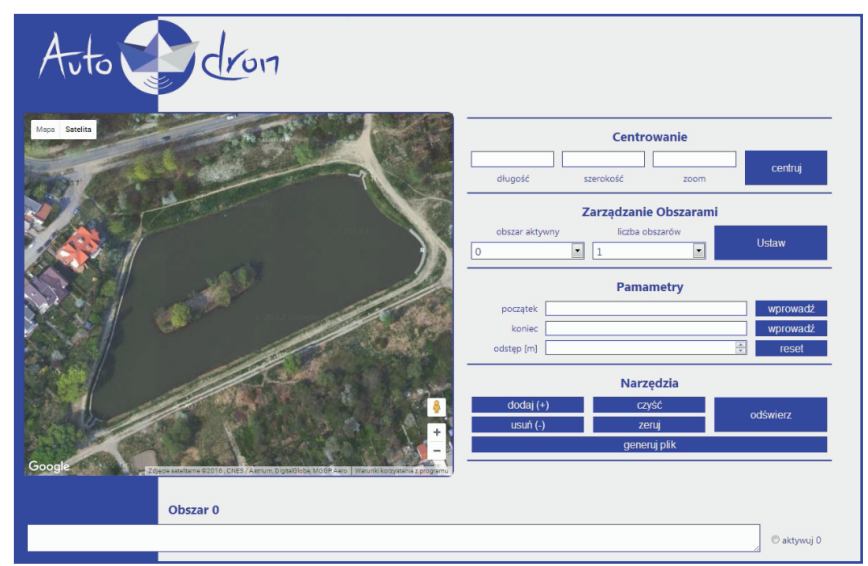

Fig. 9. Application user interface for planning the measurement campaign (own study)

\section{BATHYMETRIC MEASUREMENT OF THE RETENTION RESERVOIR AND MEASUREMENT DATA PROCESSING}

Before commencing bathymetric measurements, the single beam echo sounder (SonarMite MILSpec) and the GNSS geodetic receiver (Trimble R10) with the controller (Trimble TSC3) had to be configured. For this purpose, the transducer was connected (using the IP67 cable) with the echo sounder and then the receiver and the echo sounder were paired with the controller using short-range wireless communication (Bluetooth).

Then, in order to verify the correctness of the single beam echo sounder indications, its calibrating (taring) was performed, and the draft of the transducer was defined, which is one of the components of the depth measurement [10]. Another needed parameter is the speed of sound in water [11]. This parameter could not be experimentally determined due to the lack of ultrasound measuring instrument (the value of $1500 \mathrm{~m} / \mathrm{s}$ is set by default). Fortunately, this value had no significant impact on the accuracy of the performed measurements (the maximum recorded depth was only $1.57 \mathrm{~m}$, therefore the depth measurement error was of an order of several $\mathrm{cm}$ ). Regarding the applied measuring equipment, it is worth quoting the basic parameters of the echo sounder, such as the frequency: $200 \mathrm{kHz}$; the minimum operating range: $30 \mathrm{~cm}$; and the depth measurement error: $1 \mathrm{~cm}+0.5 \%$ depth (RMS). These technical characteristics meet national and international recommendations regarding echo sounders $[16,21]$.

Another aspect of bathymetric measurements is precise positioning of the measuring point. For this purpose, the GNSS geodetic receiver was applied which makes use of all Global Navigation Satellite Systems (GPS, GLONASS, BDS, Galileo), Satellite Based Augmentation Systems, as well as GNSS geodetic networks. As a result, the average number of satellites received by the receiver ranged typically within 16-20 units, resulting in the ability to make precise positioning in hydrographic survey on the level of $1-2 \mathrm{~cm}$ (RMS) $[1,2$, 23, 24].

After configuring the measuring equipment, the bathymetric measurements commenced. The test area covered the retention reservoir in the Gdansk Morena district, at Wilenska Street. In order to create a precise bathymetric (contour) map, the scope of measurement also included geodetic measurements of the coastline of the reservoir. The GNSS receiver mounted on the measuring pole (Fig. 11) was used for this purpose. Then, using a commercial RTK service of the VRSNet.pl [3] company, Internet connection to the reference station in Gdansk was initiated using mobile phone network (GPRS). During the research carried out on August 08, 2016, 119 points were measured. The obtained data were stored on the SD card (in the controller) in .job format. Next, the recorded measurement points were imported to the geodetic software Trimble Business Center (commonly used for measurement data processing, the so-called post-processing) $[19,20]$. Processing parameters of the measurement data and projections are presented in Fig. 10. The processing based on: the Gauss-Krüger projection [4], the plane rectangular 
coordinate system 2000 [15], the height system Kronstadt 86 [28], and the quasigeoid model PL-geoid-2011 [8].

\begin{tabular}{|c|c|}
\hline Country & Poland \\
\hline System/zone & W000/18 \\
\hline Reference ellipsoid & WGS 84 \\
\hline Ellipsoid semi-major axis & 0.0033528137 \\
\hline Ellipsoid flattening & Gauss-Krüger \\
\hline Projection & 0 \\
\hline Latitude of origin & 18 \\
\hline Central meridian & 0 \\
\hline False Northing & 6500000 \\
\hline False Easting & 0.999923 \\
\hline Scale factor & North \\
\hline Azimuth & Rising northeast \\
\hline Grid orientation & Geoid \\
\hline Transformation of elevation & PL-geoid-2011 \\
\hline Geoid model & Kronstad \\
\hline Reference system & \\
\hline
\end{tabular}

Fig. 10. Report on data processing during measurements of the coastline of the retention reservoir in Gdansk (own study)

The processed measurement data determined the coastline of the artificial water reservoir (Fig. 11). As illustrated in the figure, the outline of the measured retention reservoir does not coincide with that observed in the satellite photo (provided by the Google Earth Pro platform), which was taken on April 11, 2016, by the Landsat 8 satellite under the program for acquisition of satellite imagery of Earth (Landsat). It is noteworthy that the outlines of the reservoir overlap almost entirely, except for the viewing pier which, as seen in Fig. 11, is clearly shifted. The reason for this may be the fact that it is a floating pier so its position can change. What is interesting, at the corner points of the satellite photo of the pier there are steel piles designed to stabilize the floating structure. Therefore, it is almost certain that the pier in the past few months had been deliberately shifted and the satellite images are highly accurate [13]. Such a situation can lead to the damage of the autonomous survey vessel (drone) that uses the route planning software based on satellite images from Google. The only solution to this problem is the most frequent update of satellite images.
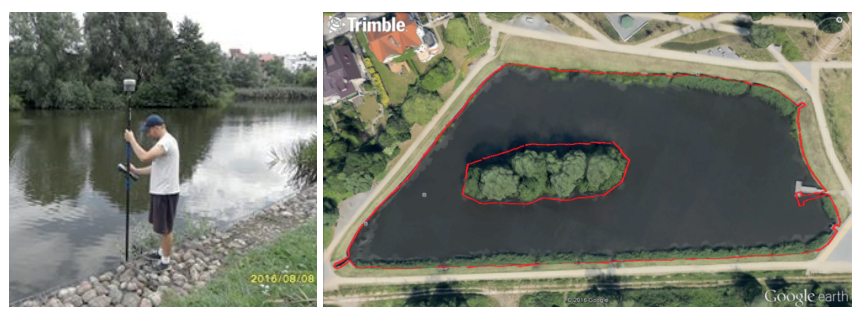

Fig. 11. Staking out the coastline point (left) and the coastline of the retention reservoir, measured and obtained from the Google Earth Pro platform (right) (own study).
The results of the research of August 8, 2016, were taken into account when planning the drone route during the next measurement campaign on September 3, 2016. Its objective was to create a digital bottom model based on triangle mesh (Fig. 12) and bathymetric (contour) map of the retention reservoir (Fig. 13). In less than two hours the drone measured 2222 points in autonomous/hand mode. Then the measurement data were processed in the TBC software, using the same parameters as in Fig. 10.

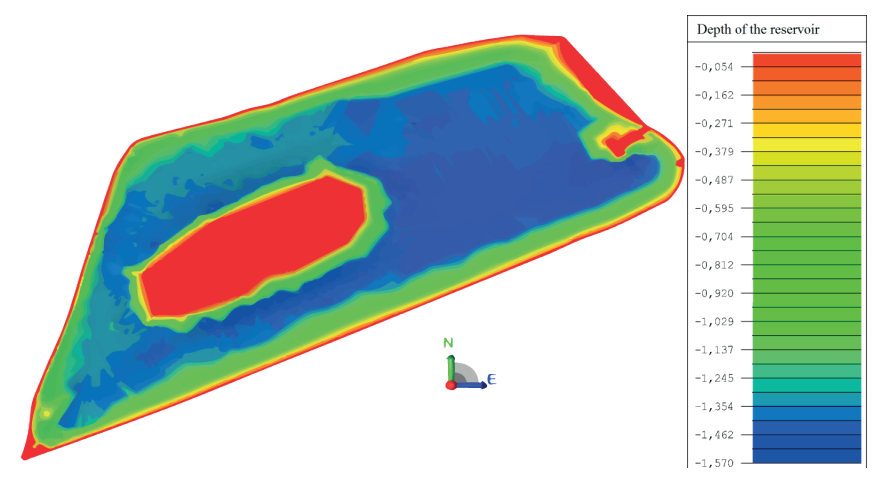

Fig. 12. Digital bottom model of the retention reservoir in Gdansk (own study)

The area of the reservoir is $1.17 \mathrm{ha}$, the length is $525 \mathrm{~m}$, and the maximum depth is $1.57 \mathrm{~m}$. It is characterized by a steep shore (at a distance of 4-8 meters from the coastline there is a sudden drop in depth to the $1.4 \mathrm{~m}$ contour line) and a flat bottom (almost the entire area of the reservoir lies at the depth of 1.4-1.57 m) (Figs. 12 and 13). It is noteworthy that in Figs. 13 and 14 the contour lines are placed at every $10 \mathrm{~cm}$ (within the range of $0-1.5 \mathrm{~m}$ ).

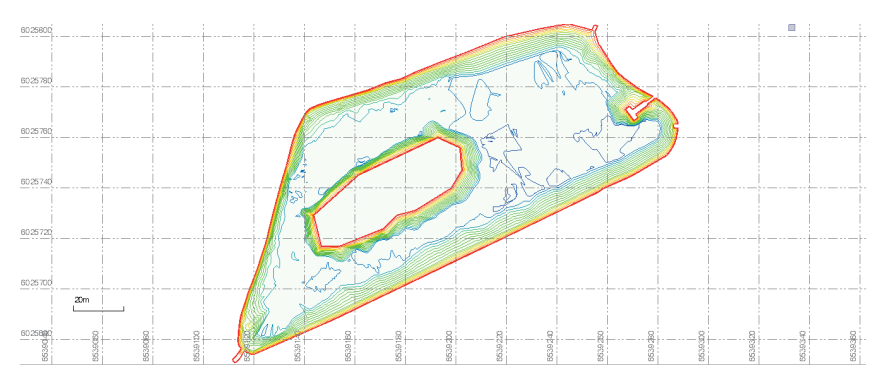

Fig. 13. Bathymetric (contour) map of the retention reservoir in Gdansk in the 2000 system (own study)

Because isometric illustration using the Google platform is widely used today, hence the obtained results were exported to. $\mathrm{kmz}$ format, which allows the presentation of the results from the application of this platform. 


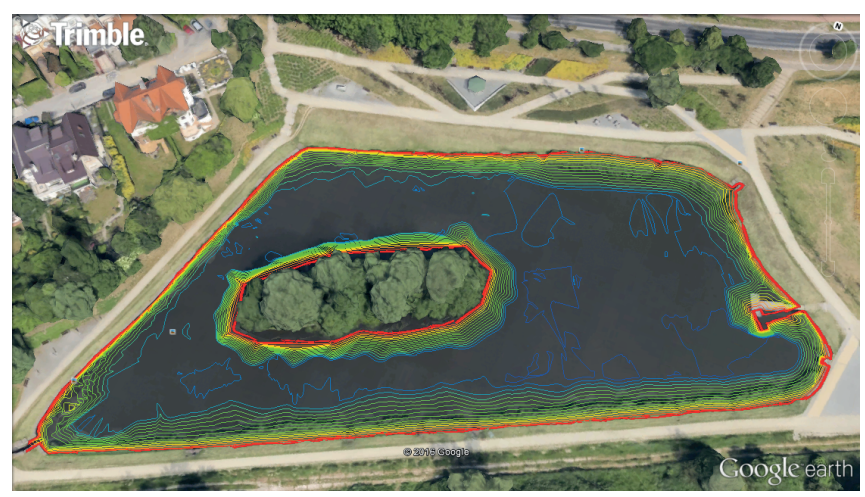

Fig. 14. Isometric projection of the retention reservoir in Gdansk with the marked coastline and contour lines (own study)

\section{CONCLUSIONS}

When modernising the survey vessel and performing bathymetric measurements, the authors encountered a number of difficulties. The applied autopilot was not designed to work in water environment which led to the rounding of measurement profiles. An additional impact here was the inaccurate GPS position (a several-meter error) obtained from the module dedicated to the Pixhawk autopilot. Therefore, in future works the authors intend to change the autopilot and connect it to the GNSS geodetic receiver. It also turned out that the hydrographic drone weighing approx. $20 \mathrm{~kg}$ (including the measuring equipment) is characterized by low seakeeping. Consequently, the time of measurements and hydrometeorological conditions played an important role, hence the measurements were carried out in calm weather with little waving. In addition, when planning a further measurement campaign, use will have to be made of most recent satellite images because, as shown by experience gained from the implementation of the project, situations can occur which will lead to the damage of the autonomous survey vessel.

In terms of measuring, the document regulating the conduct of hydrographic surveys is the IHO S-44 standard [7]. This document does not, however, define the method for determining the shape of the bottom of an inland reservoir and does not assign minimum accuracy requirements for this type of measurements. Nevertheless, the accuracy of the proposed solution (bathymetric measurements implemented using a single beam echo sounder and GNSS geodetic networks) can be considered entirely satisfactory [17, 18]. It is noteworthy here that, at present, none of the respective institutions in Poland (maritime offices, Hydrographic Office of the Polish Navy) has a hydrographic vessel capable of carrying out bathymetric measurements for shallow waters (at depths below $1 \mathrm{~m}$ ).

\section{ACKNOWLEDGEMENTS}

This scientific work was financed from the budget for science in years: 2016-2020, as a research project within the frameworks of the „Diamond Grant” programme.

\section{REFERENCES}

1. Bakuła M., Przestrzelski P. (2013), Technology of Reliable RTK GPS/GLONASS Positioning, Geodesic Review, No. 7, pp. 3-9 (in Polish).

2. Bakuła M., Przestrzelski P., Kaźmierczak R. (2015), Reliable Technology of Centimeter GPS/GLONASS Surveying in Forest Environments, IEEE Transactions on Geoscience and Remote Sensing, Vol. 53(2), pp. 1029-1038.

3. Ćwiąkała P., Gabryszuk J., Krawczyk K., Krzyżek R., Leń P., Oleniacz G., Puniach E., Siejka Z., Wójcik-Leń J. (2015), GNSS Technology and Its Application in Setting Out Surveys and Monitoring, Rzeszów School of Engineering and Economics Publishing House, Rzeszów (in Polish).

4. Deakin R. E., Hunter M. N., Karney C. F. F. (2010), The Gauss-Krüger Projection, Proceedings of the $23^{\text {rd }}$ Victorian Regional Survey Conference, Warrnambool.

5. Elliot W. (2014), Programming AVR Microcontrollers for Practitioners, Helion Publishing House, Gliwice (in Polish).

6. Guze S., Neumann T., Wilczyński P. (2017), Multi-Criteria Optimization of Liquid Cargo Transport According to Linguistic Approach to the Route Selection Task, Polish Maritime Research, Vol. 24(s1), pp. 89-96.

7. IHO (2008), IHO Standards for Hydrographic Surveys, Special Publication No. 44, $5^{\text {th }}$ Edition.

8. Kadaj R. (2014), Design of the Quasigeoid Model PL-geoid-2011, Seminar of the Committee on Geodesy of the Polish Academy of Sciences and the Faculty of Geodesy and Cartography at Warsaw University of Technology: „Realization of Geodetic Control Networks and Geodynamic Problems", Grybów (in Polish).

9. Kazimierski W., Włodarczyk-Sielicka M. (2016), Technology of Spatial Data Geometrical Simplification in Maritime Mobile Information System for Coastal Waters, Polish Maritime Research, Vol. 23(3), pp. 3-12.

10. Makar A. (2002), Shallow Water Geodesy: Survey Errors During Seabed Determination, Reports on Geodesy, No. 2(62), pp. 71-78.

11. Makar A. (2008), Method of Determination of Acoustic Wave Reflection Points in Geodesic Bathymetric Surveys, Annual of Navigation, No. 14, pp.1-89. 
12. Makar A., Naus K. (2003), Obtaining of Data for Digital Sea Bottom Model, Archives of Photogrammetry, Cartography and Remote Sensing, Vol. 13A, pp. 163-170 (in Polish).

13. Mohammed N. Z., Ghazi A., Mustafa H. E. (2013), Positional Accuracy Testing of Google Earth, International Journal of Multidisciplinary Sciences and Engineering, Vol. 4, No. 6, pp.6-9.

14. Moszyński M., Chybicki A., Kulawiak M., Łubniewski Z. (2013), A Novel Method for Archiving Multibeam Sonar Data with Emphasis on Efficient Record Size Reduction and Storage, Polish Maritime Research, Vol. 20(1), pp. 77-86.

15. Osada E. (2016), Geodetic Datums, UxLAN Publishing House, No. 3, Wroclaw (in Polish).

16. PN-EN ISO 9875:2005, Vessels and Maritime Technology - Echo Sounders (in Polish).

17. Popielarczyk D. (2012), RTK Water Level Determination in Precise Inland Bathymetric Measurements, Proceedings of the $25^{\text {th }}$ International Technical Meeting of the Satellite Division of the Institute of Navigation (ION GNSS 2012), Nashville, pp. 1158-1163.

18. Popielarczyk D. (2016), Accuracy of Vertical Trajectory Determination of Hydrographic Survey Unit Using Robotized Total Station, Proceedings of the $16^{\text {th }}$ International Multidisciplinary Scientific GeoConference \& EXPO SGEM2016, Albena, pp. 39-46.

19. Popielarczyk D., Templin T. (2014), Application of Integrated GNSS/Hydroacoustic Measurements and GIS Geodatabase Models for Bottom Analysis of Lake Hancza: the Deepest Inland Reservoir in Poland, Pure and Applied Geophysics, Vol. 171(6), pp. 997-1011.

20. Popielarczyk D., Templin T., Łopata M. (2015), Using the Geodetic and Hydroacoustic Measurements to Investigate the Bathymetric and Morphometric Parameters of Lake Hancza (Poland), Open Geosciences, Vol. 7(1), pp. 854-869.

21. PRS (2015), Rules for Statutory Survey of Sea-going Ships. Part V - Navigation Devices, Gdansk (in Polish).

22. Romano A., Duranti P. (2012), Autonomous Unmanned Surface Vessels for Hydrographic Measurement and Environmental Monitoring, Proceedings of the FIG Working Week, Rome.

23. Specht C., Koc W., Smolarek L., Grządziela A., Szmagliński J., Specht M. (2014), Diagnostics of the Tram Track Shape with the Use of the Global Positioning Satellite Systems (GPS/GLONASS) Measurements with a $20 \mathrm{~Hz}$ Frequency Rate, Journal of Vibroengineering, Vol. 16(6), pp. 3076-3085.
24. Specht C., Specht M., Dąbrowski P. (2017), Comparative Analysis of Active Geodetic Networks in Poland, Proceedings of the $17^{\text {th }}$ International Multidisciplinary Scientific GeoConference \& EXPO SGEM2017, Albena, pp. 163-176.

25. Specht C., Weintrit A., Specht M. (2016), Determination of the Territorial Sea Baseline - Aspect of Using Unmanned Hydrographic Vessels, TransNav - The International Journal on Marine Navigation and Safety of Sea Transportation, Vol. 10, No. 4, pp. 649-654.

26. Specht M. (2016), Determination of the Polish Territorial Sea Baseline, Master's Thesis, Gdynia Maritime University (in Polish).

27. Tuna G., Arkoc O., Koulouras G., Potirakis S. M. (2013), Navigation System of an Unmanned Boat for Autonomous Analyses of Water Quality, Elektronika i Elektrotechnika, Vol. 19, No. 8, pp. 3-7.

28. Wyrzykowski T. (1988), Monograph on Domestic $1^{\text {st }}$ Class Precise Levelling Networks, Institute of Geodesy and Cartography, Warsaw (in Polish).

29. Yan-na Z., Ti-kun S., Fei D., Wei-min Y. (2015), The Design of ARM-Based Control System of Unmanned Research Catamaran, In: Kim J.-H. et al. (eds.), Robot Intelligence Technology and Applications 3, Advances in Intelligent Systems and Computing 345, Springer International Publishing, Cham, pp. 617-623

30. Zienkiewicz M. H., Czaplewski K. (2017), Application of Square $\mathrm{M}_{\text {split }}$ Estimation in Determination of Vessel Position in Coastal Shipping, Polish Maritime Research, Vol. 24(2), pp. 3-12. 


\section{CONTACT WITH THE AUTHORS}

\section{Cezary Specht}

e-mail:c.specht@geodezja.pl Akademia Morska w Gdyni Morska 81-87, 81-225 Gdynia

\section{Poland}

\section{Emilian Switalski}

e-mail:switalski.emilian@gmail.com

Akademia Morska w Gdyni Morska 81-87, 81-225 Gdynia

\section{Poland}

\section{Mariusz Specht}

e-mail:m.specht@wn.am.gdynia.pl

Akademia Morska w Gdyni

Morska 81-87, 81-225 Gdynia

Poland 